\title{
Cell Cycle Regulation Pathway
}

National Cancer Institute

\section{Source}

National Cancer Institute. Cell Cycle Regulation Pathway. NCI Thesaurus. Code C39700.

A representation of the sequence of biological or biochemical events that are involved in the regulation of the cell cycle. 